\title{
DETERMINAÇÃO DA MASSA MOVIMENTADA EM MODELO A FRIO DO BANHO METAL ESCORIA POR SOPRO SUPERSÔNICO DE BICOS MULTIFUROS*
}

\author{
Breno Totti Maia ${ }^{1}$ \\ Caio Nogueira Araújo Diniz ${ }^{2}$ \\ Gustavo Germano Pereira² \\ Raissa Salgado ${ }^{2}$ \\ Roberto Parreiras Tavares ${ }^{3}$
}

\section{Resumo}

A principal ferramenta de controle do processo BOF reside na regulagem dos parâmetros de sopro de oxigênio. As condições ótimas desse processo envolvem diversas variáveis, como vazão de oxigênio, distancia banho lança (DBL), número de furos para a saída de oxigênio na lança, entre outros fatores. Através de uma análise visual da penetração do jato e do volume movimentado, foram analisados os comportamentos para cada configuração de sopro entre diferentes combinações de bicos multifuros (3 a 6 furos), para uma distância banho lança (DBL) e vazão constantes. A análise dos parâmetros de interação entre o sopro e o banho líquido composta pelas frações de metal e escória, representados respectivamente por água e óleo de parafina é o principal objetivo deste trabalho. Foi necessário desenvolver nova metodologia para a determinação da penetração assim como proposta de nova fórmula e ajuste da constante empírica, fator $\mathrm{K}$. As maiores penetrações foram alcançadas com os bicos de 3 e 4 furos. Para a configuração de 6 furos, foram encontrados os menores valores de penetração e maior volume de zonas de baixa movimentação em relação aos parâmetros estabelecidos.

Palavras-chave: BOF; Modelo a frio; Penetração de jato; Zonas estagnadas; Fator K.

\section{MASS MOVEMENT DETERMINATION BY METAL SLAG BATH COLD MODEL BY SUPERSONIC BLOW FROM MULTI NOZZLES}

\section{Abstract}

The primary control tool of the BOF process lies on the adjustment of the oxygen blow parameters. The best process conditions involve several variables, like oxygen flow rate, distance bath lance (DBL), number of holes for the oxygen blow, among other factors. Through a visual inspection of the jet penetration and the volume of stagnant zones, the behavior of each configuration tested was analyzed using different sets of nozzles (3 to 6 holes), and with constant distance bath lance (DBL) and flow rate. The analysis of the interaction parameters between the oxygen blow, the molten metal and slag, represented respectively by water and paraffin oil, is the main objective of the present work. It was necessary to develop a new methodology in order to determine the penetration, propose a new formula and adjust the empirical constant, called $\mathrm{K}$ factor. The highest penetration were achieved for the nozzles with 3 and 4 holes. The lowest penetration and the highest volume of stagnant zones were represented for the configuration of 6 holes.

Keywords: BOF; Cold model; Jet penetration; Stagnant zones; K factor.

1 Sócio da ABM; Engenheiro Metalurgista e Doutor Pesquisador da LUMAR METALS, Belo Horizonte, MG, Brasil.

2 Aluno de Graduação do Curso de Engenharia Metalúrgica da UFMG, Belo Horizonte, MG, Brasil.

3 Sócio da ABM; Engenheiro Metalurgista; Professor Doutor do Departamento de Engenharia Metalúrgica da UFMG, Belo Horizonte, MG, Brasil. 


\section{INTRODUÇÃO}

O processo de refino primário via convertedor BOF (Basic Oxygen Furnace), representa o meio mais utilizado industrialmente na produção de aço. Diante um cenário desafiador, novas tecnologias e técnicas industriais vêm surgindo com o objetivo de tornar o processo mais competitivo e economicamente viável. Segundo Seshadri et al. ${ }^{[1]}$, métodos de experimentação na planta industrial representam um alto custo, podendo gerar problemas como a quebra da rotina operacional de uma planta, queda de produtividade e um grande risco ao processo. A partir de técnicas de modelagem física, é possível recriar modelos de reatores em pequena escala e que podem ser operados em laboratório, a um custo bem menor do que um experimento em planta industrial. Pode-se dizer que os resultados gerados, por modelos a frio em laboratório, são aplicáveis à prática industrial quando existe semelhança entre o modelo (operado em laboratório) e protótipo (reator industrial), como também a semelhança entre alguns números adimensionais que representam os critérios de similaridade. Os fenômenos fluidodinâmicos que ocorrem no interior de convertedor BOF apresentam alta complexidade, especialmente devido a interação gás-metal-escória. A figura 1 exemplifica alguns fenômenos decorrentes dessa interação.

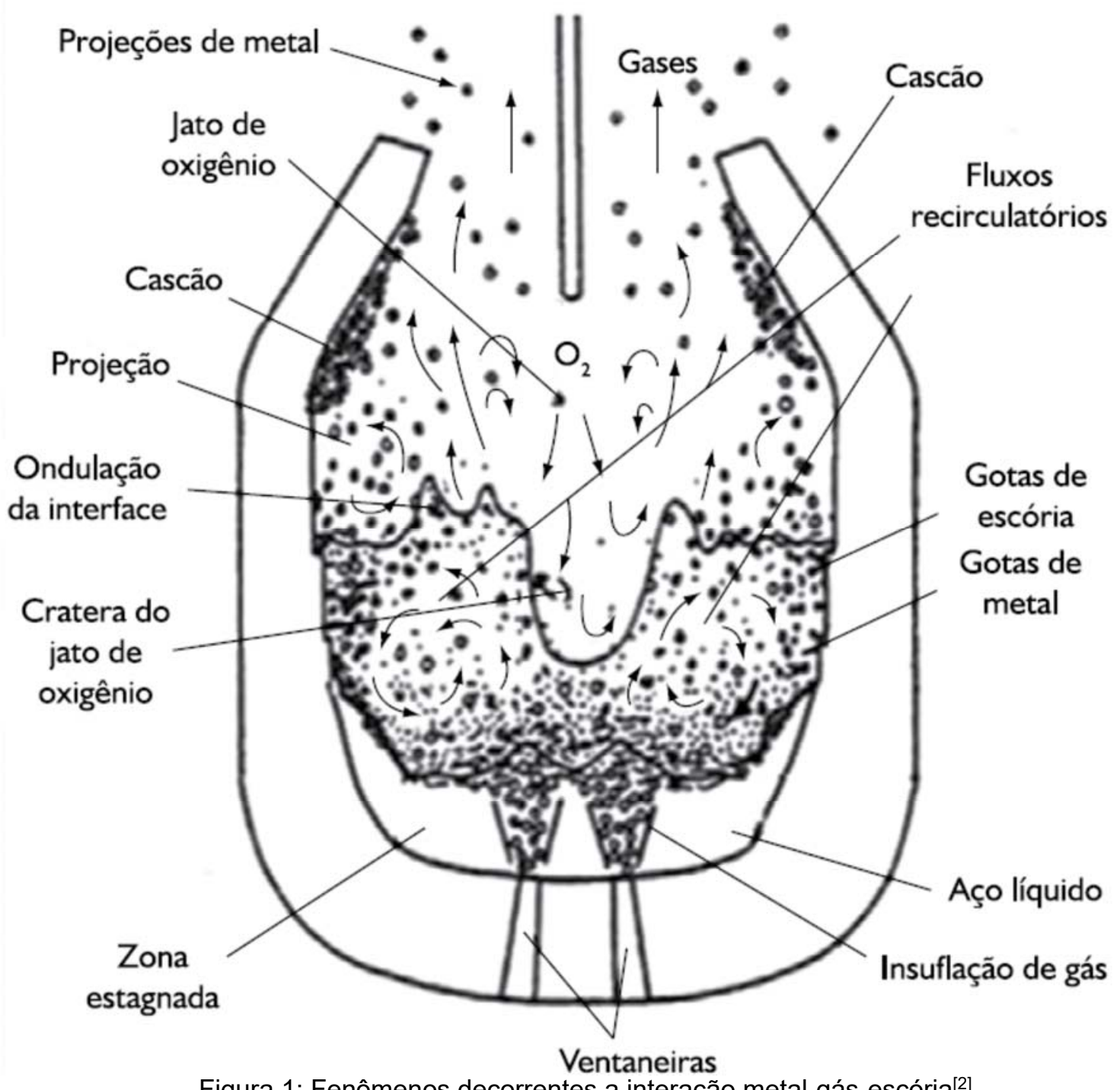

Figura 1: Fenômenos decorrentes a interação metal-gás-escória ${ }^{[2]}$ 
Cerca de $60 \%$ do tempo total de uma corrida no convertedor BOF está ligado ao sopro de oxigênio, que representa um fator operacional chave no processo de refino primário. A diminuição do tempo de sopro gera um aumento de produtividade, além de grande economia. Para que seja possível diminuir o tempo de sopro, é necessário que ocorra um aumento na taxa de descarburacao do banho ${ }^{[3]}$. Visando tais objetivos, esse trabalho foi conduzido alterando as configurações do bico de sopro em um modelo a frio de convertedor BOF, analisando a interação do jato de ar com o banho líquido composto por água e óleo de parafina representando aço e escória, visando encontrar as melhores condições para o processo.

\section{MATERIAIS E MÉTODOS}

\subsection{Modelagem Física}

Para a realização da simulação do convertedor LD foi utilizado um modelo de acrílico em escala 1/8 de um convertedor de 220t, que se encontra no Laboratório de Simulação de Processos, UFMG (LaSiP - Departamento de Engenharia Metalúrgica e de Materiais da UFMG). As dimensões do modelo são apresentadas na Figura 2.

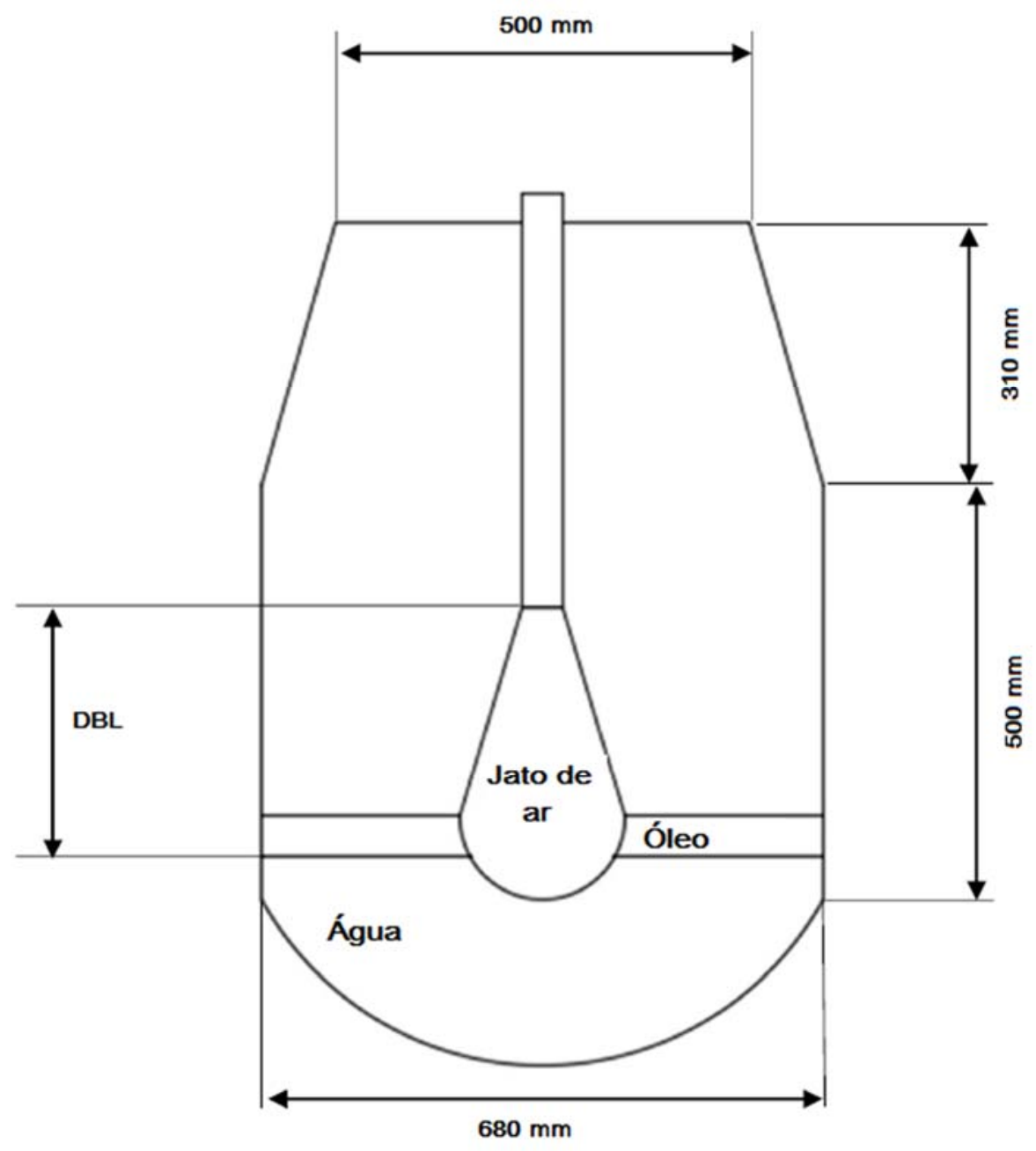

Figura 2 - Dimensões do modelo físico do convertedor ${ }^{[3]}$.

Na simulação do sopro da lança, foi utilizado um compressor de $22,5 \mathrm{~kW}$ com uma vazão fixa para todos os testes de $130 \mathrm{~m}^{3} / \mathrm{h}$. Para controlar a vazão do jato da lança foram utilizados medidores de vazão. A distância banho lança (DBL) foi de $380 \mathrm{~mm}$, 
simulando a altura utilizada em algumas indústrias. Em cada teste, alterou-se apenas o bico de saída de ar da lança, variando entre 3, 4, 5 e 6 furos e com ângulos de 8, 10, 15 e 17,5', respectivamente. A geometria interna do bocal é constituída de trecho convergente seguido de um segmento reto curto, onde se encontra o diâmetro crítico e ao fim um trecho divergente, como é detalhado na figura 3.
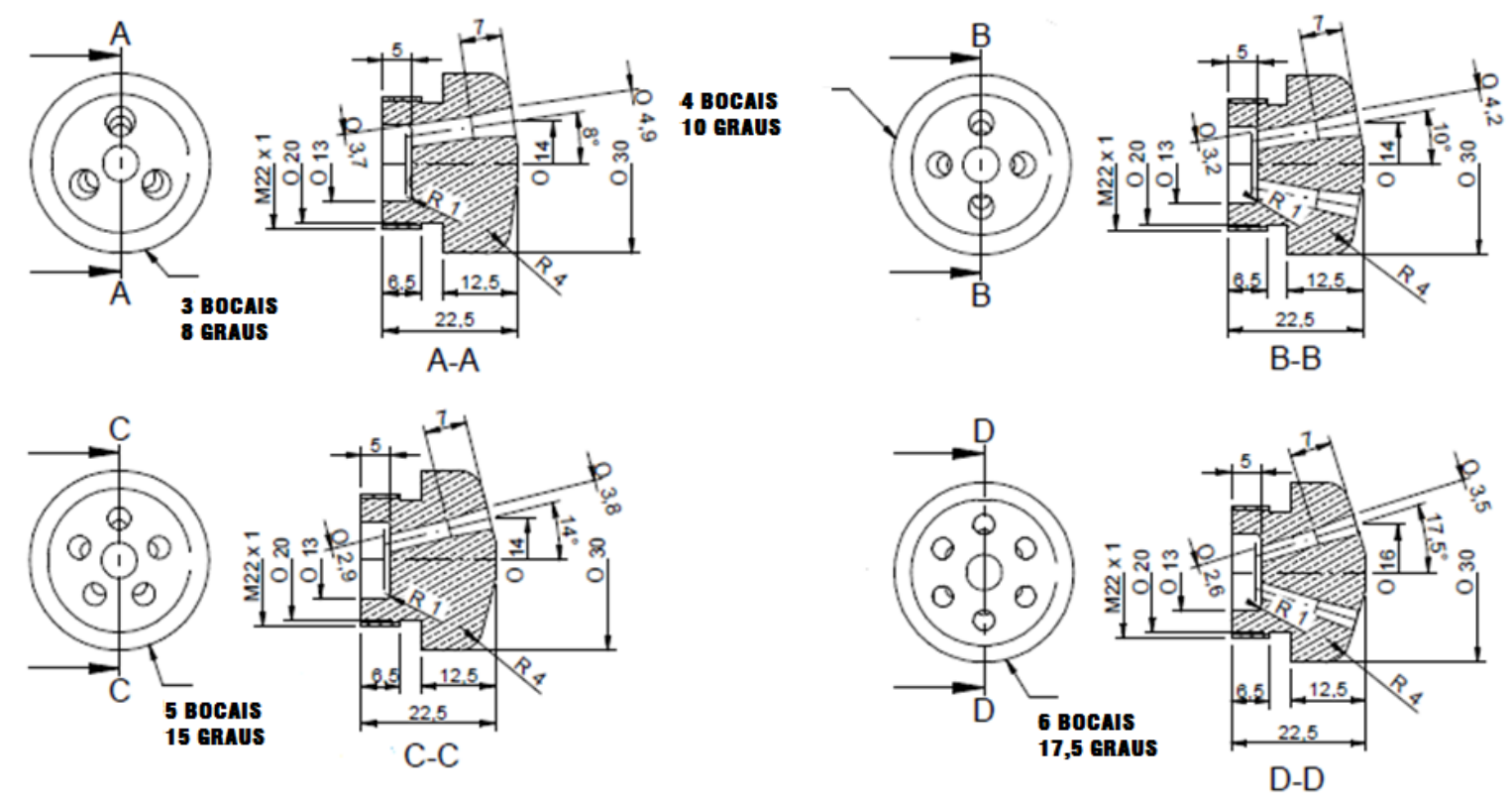

Figura 3: Geometria interna do bocal.

Objetivando as melhores condições para simular o processo de refino primário, utilizou-se óleo de parafina e água para representar escoria e aço respectivamente. Tais fluidos foram escolhidos devido às suas características físicas semelhantes às das fases encontradas no processo de refino, podendo assim gerar uma maior similaridade dinâmica entre os testes e a prática industrial ${ }^{[4]}$. A tabela 1 apresenta a comparação entre os números adimensionais usados para a semelhança dinâmica entre o modelo a frio e a pratica industrial.

Tabela I - Números adimensionais

\begin{tabular}{|c|l|c|c|c|}
\hline & & Industrial & Modelo & Significado \\
\hline $\mathrm{Fr}^{*}$ & Froude Modificado & 0,069 & 0,164 & $\begin{array}{c}\text { (forças inerciais)/ } \\
\text { (forças gravitacionais) }\end{array}$ \\
\hline $\mathrm{Re}^{*}$ & Reynolds Modificado & $6,936^{*} 10^{5}$ & $1,055^{*} 10^{5}$ & $\begin{array}{c}\text { (forças inerciais)/ } \\
\text { (forças viscosas) }\end{array}$ \\
\hline $\mathrm{We}^{*}$ & Weber Modificado & $4,771^{*} 10^{3}$ & $1,370^{*} 10^{3}$ & $\begin{array}{c}\text { (forças inerciais)/ } \\
\text { (forças de tensão superficial) }\end{array}$ \\
\hline $\mathrm{Ma}$ & Número de Mach & 2,07 & 1,79 & Fluxos compressíveis. \\
\hline
\end{tabular}

\subsection{Procedimentos}

Para realização dos testes, o modelo físico é preenchido com água até a distância de $250 \mathrm{~mm}$ do fundo, e então o jato de ar é liberado a fim de ajustar a vazão para $130 \mathrm{Nm}^{3} / \mathrm{h}$. Com a vazão ajustada pelo primeiro registro de saída de ar, fecha-se o segundo registro. A partir do momento que o banho se encontra estabilizado, 
adiciona-se uma camada de $30 \mathrm{~mm}$ de óleo de parafina, que rapidamente se separa da água, gerando uma clara distinção entre as fases, como ilustrado na figura 4.

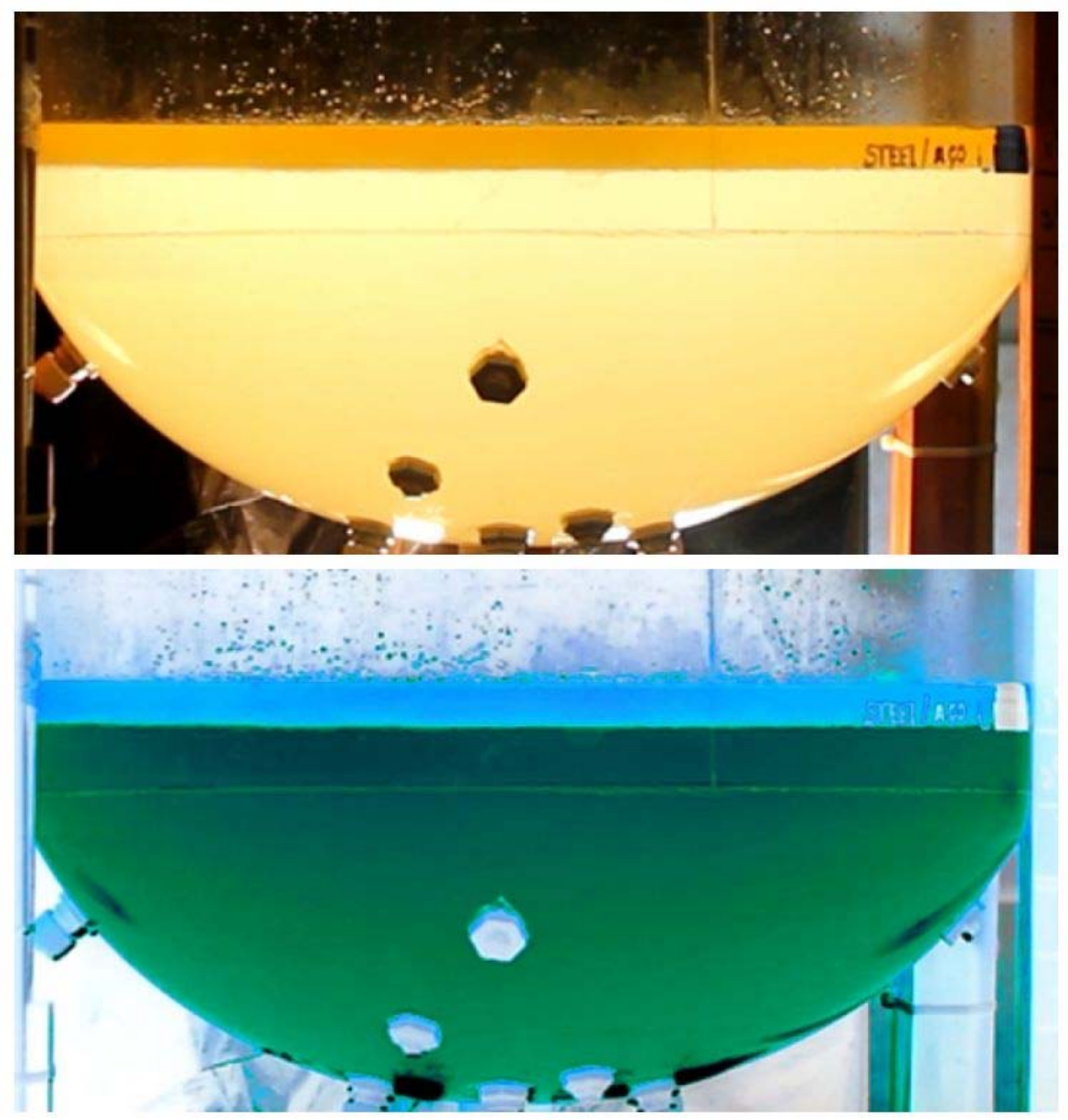

Figura 4: Separação entre as fases água e óleo. a) original; b) com contraste,

Também são adicionados ao banho $150 \mathrm{~g}$ de sabão em pó da marca Brilhante ${ }^{\circledR}$, sendo este responsável por gerar uma emulsão durante o sopro, que objetiva reproduzir a emulsão típica do processo industrial durante a descarburação no convertedor BOF. Duas câmeras são posicionadas para filmar o comportamento do banho em contato com o jato de ar, uma frontal ao modelo e outra sobre o modelo, para que se possa observar o jato em contato com o banho da melhor maneira possível. Dois refletores são posicionados na parte de trás do modelo, gerando assim um melhor contraste para as filmagens.

\subsection{Medição da penetração do jato e volume misturado}

Para edição dos vídeos, utilizou-se o software Movie Studio Platinum ${ }^{\circledR}$, que possibilitou uma captura das imagens nos intervalos de tempo estabelecidos. A partir do momento de início de sopro, as imagens foram capturadas no intervalo de 5 segundos, tornando possível obter os valores de penetração e de volume misturado. Com as imagens capturadas, gerou-se um contraste pelo o software GIMP®, possibilitando um resultado mais preciso dos valores medidos. A fim de mensurar a penetração do jato de ar no banho e o volume deslocado, utilizou-se o software Image $\mathrm{J}^{\circledR}$, onde estabeleceu-se como penetração o volume deslocado pelo jato a partir da linha "slag" como ilustrado na figura 5. 

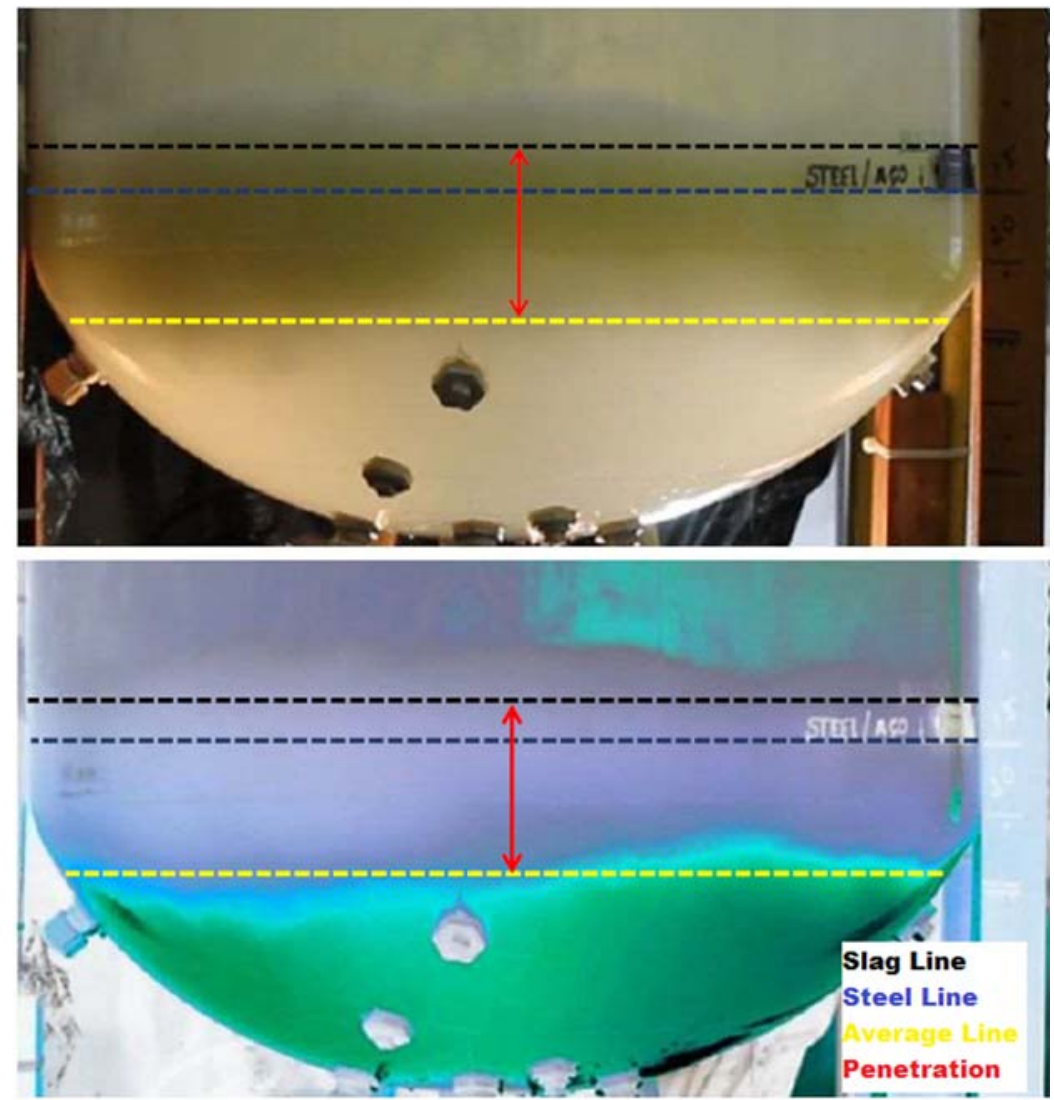

Figura 5: Definições da linha Slag, Linha Steel, Linha Media e Penetração para: a) imagem original e b) com contraste.

A figura 5 ilustra os conceitos pré-estabelecidos para medição da penetração, como as linhas "slag", "steel", média e penetração. As linhas "slag" e "steel" representam os níveis de óleo de parafina (escória) e água (aço) respectivamente. A linha média representa o ponto final médio de penetração do jato, onde a partir de uma reta centralizada na imagem partindo da linha "slag" como ponto inicial, define-se a penetração do jato no banho. As aquisições dos dados de penetração foram feitas com um intervalo de 5 segundos para cada valor. Para o mesmo intervalo de tempo, foram colhidos dados com o objetivo de analisar a porcentagem do banho que permaneceu estagnada e com isso calcular o volume misturado, como ilustrado pela figura 6.

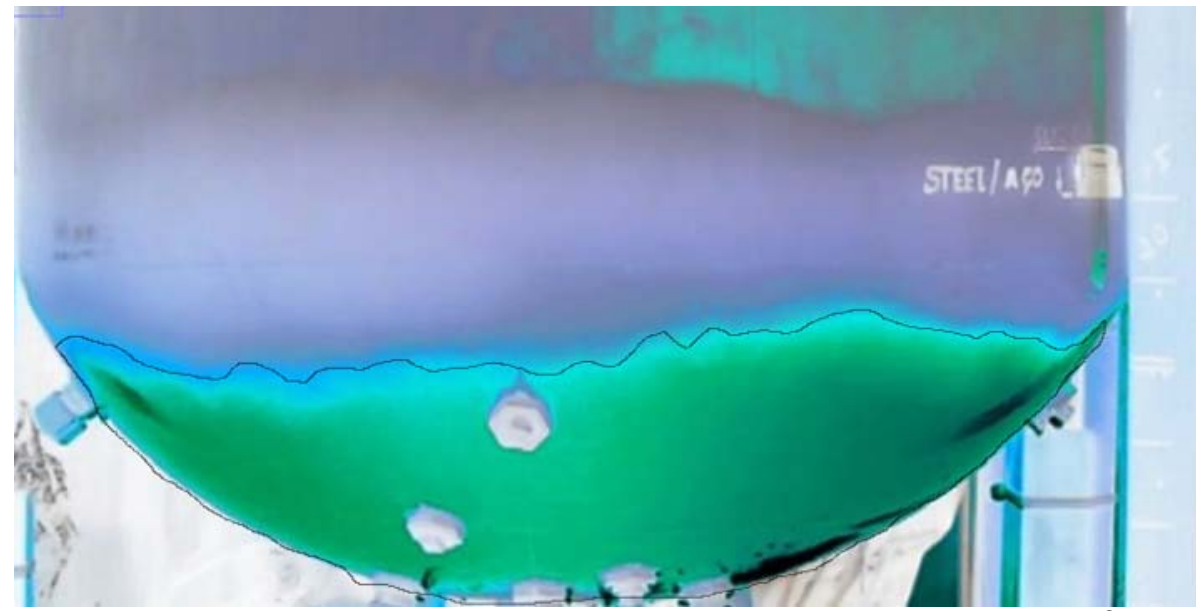

Figura 6: Volume estagnado delimitado usando o software Image ${ }^{\circledR}$. 


\subsection{Cálculo do fator $\mathrm{K}$}

Segundo $\mathrm{Maia}^{[3]}$ pode se correlacionar o número de furos de saída de oxigênio no bico da lança com o valor de penetração do jato no banho por meio de uma equação específica para sistema liquido bifásico. Nessa equação, uma evolução em relação a outros estudos $^{[5-10]}$, leva-se em conta a tensão superficial da camada de escória assim como do aço, pois tais valores influenciam diretamente na penetração do jato no banho, como demonstrado na equação 1 .

$$
\begin{aligned}
\frac{1}{K^{2}} \times\left(\frac{\pi}{2} \times \frac{P}{(D B L+P)}\right) \times\left(1+\frac{1}{P^{2}} \times \frac{\cos \theta \times\left(\sigma_{\text {STEEL }}+\sigma_{\text {SLAG }}\right)}{\left(\rho_{\text {STEEL }}+\rho_{\text {SLAG }}\right) \times g}\right)= \\
\\
\left(\frac{\pi}{4} \times \frac{\left(\rho_{\text {GAS }} \times{V_{\text {EXIT }}}^{2} \times D_{\text {EXIT }}{ }^{2} \times \cos \theta^{2} \times n\right)}{\left(\rho_{\text {STEEL }}+\rho_{\text {SLAG }}\right) \times g \times(D B L+P)^{3}}\right)
\end{aligned}
$$

Onde "K" representa uma constante empírica, "DBL" - distância banho lança (m), "P"

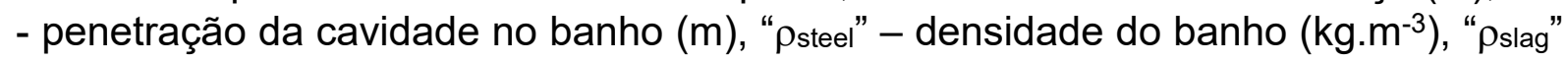
- densidade da camada de escória $\left(\mathrm{kg}^{-3} \mathrm{~m}^{-3}\right)$, " $\rho$ gas" - densidade do gás na saída do bocal $\left(\mathrm{kg} \cdot \mathrm{m}^{-3}\right)$, " $\sigma$ " - tensão superficial $\left(\mathrm{N} \cdot \mathrm{m}^{-1}\right)$, " $\mathrm{Vexit}$ - Velocidade na saída do bocal $(\mathrm{m} / \mathrm{s})$, "Dexit" - Diâmetro de saída do bocal, "g" - aceleração da gravidade $\left(\mathrm{m} . \mathrm{s}^{-2}\right)$, " $\theta$ " - Ângulo de inclinação do bocal e "n" - Número de furos no bico da lança.

Foram realizadas observações de penetração por 04 observadores de forma distinta e assim obtendo valores de média e desvio padrão das leituras e cálculos de penetração. A partir dos valores de penetração obtidos, foi possível obter o valor de K para cada configuração de teste.

\section{RESULTADOS E DISCUSSÃO}

\subsection{Penetração do jato}

A partir das imagens obtidas, foi possível estimar os valores de penetração durante o sopro de ar. Observou-se que tal valor não é constante durante todo o tempo de sopro, de maneira que o jato de ar desloca progressivamente um volume maior da mistura água, óleo e sabão para baixo.

As figuras 7, 8, 9 e 10 ilustram, de maneira comparativa, o comportamento do banho para os primeiros 20 segundos de sopro, para cada configuração de teste realizado. O volume em contraste, que apresenta cor verde/azul, representa as zonas estagnadas no banho. 

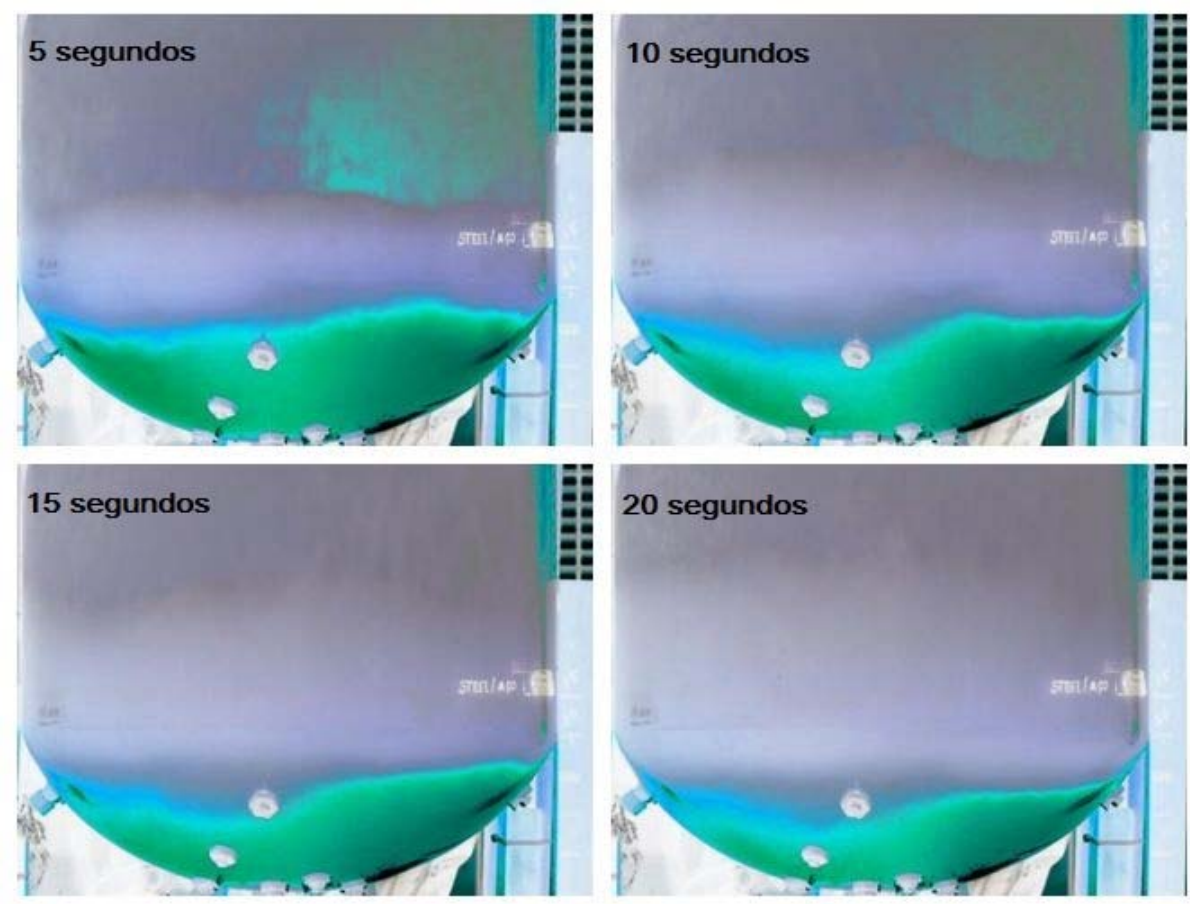

Figura 7: Primeiros 20 segundos de sopro, configuração de bico com 3 furos.

Para a configuração de teste ilustrado pela figura 7 , foram encontrados os maiores valores de penetração, à medida que o jato penetra na mistura, a emulsão gerada aumenta de maneira uniforme, se estabilizando juntamente com a penetração.

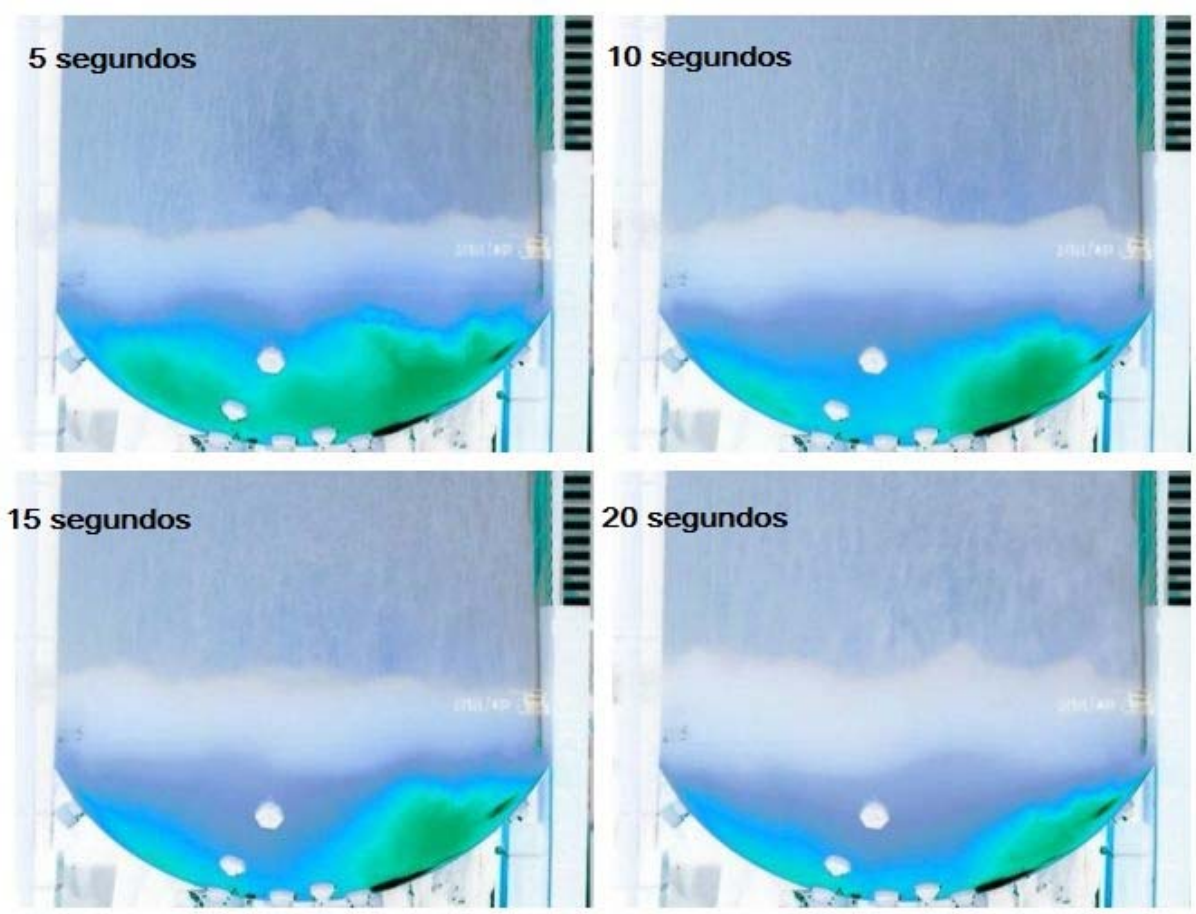

Figura 8: Primeiros 20 segundos de sopro, configuração de bico com 4 furos.

A figura 8 ilustra o teste em que se utilizou um bico com 4 furos, de modo que aumento da penetração com o decorrer do tempo tem comportamento semelhante ao teste ilustrado pela figura 7 , porem apresenta menores valores de penetração para os mesmos intervalos de tempo. Progressivamente o emulsão gerada pela 
mistura agua, óleo e sabão em pó toma conta de grande parte do banho, fazendo com que as áreas verdes/azuis, que representam as zonas estagnadas, desapareçam.
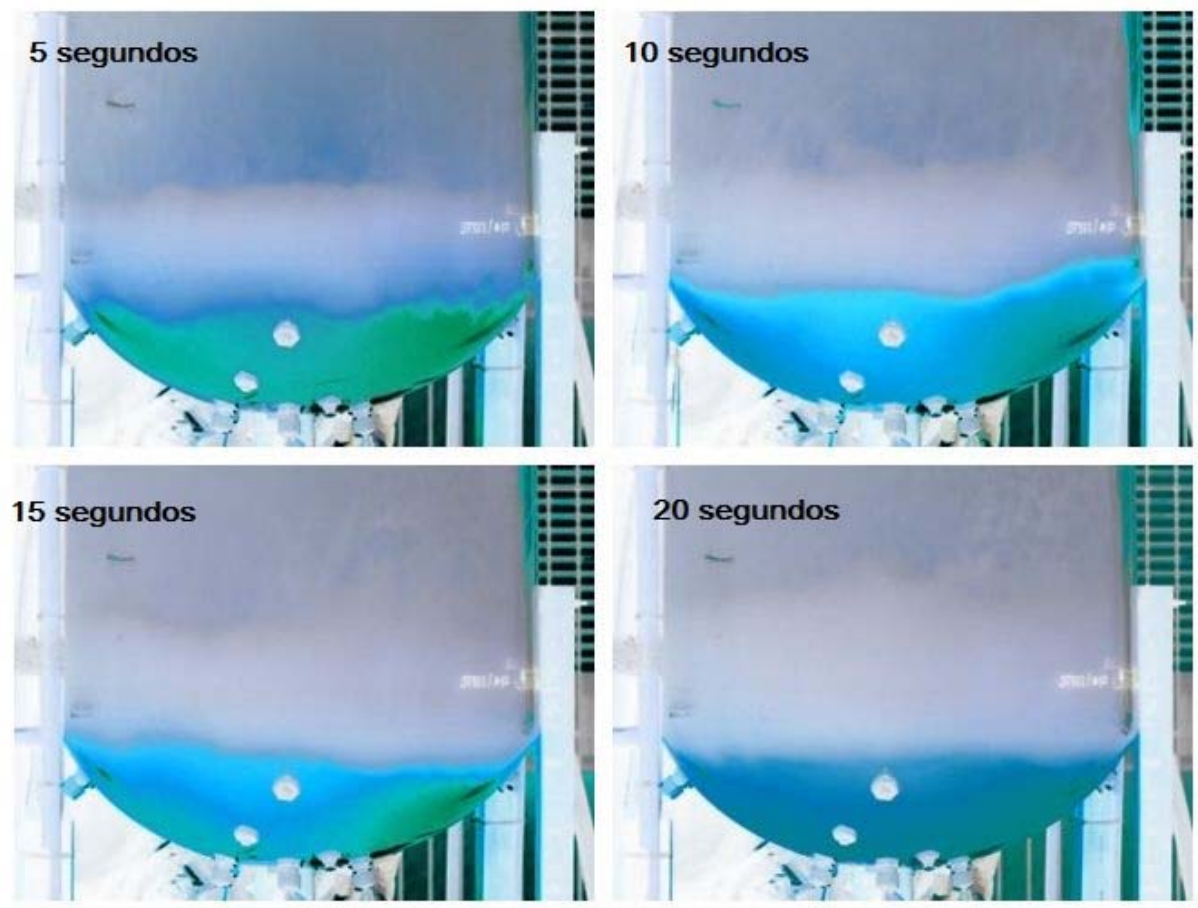

Figura 9: Primeiros 20 segundos de sopro, configuração de bico com 5 furos.

Para a configuração de teste com bico de 5 furos, pode-se observar que o jato de ar penetra no banho mais lentamente, quando comparado com os testes das figuras 7 e 8, gerando de forma uniforme uma emulsão que aumenta à medida que o jato de ar penetra cada vez mais no banho, até o momento em que ambos se estabilizam.
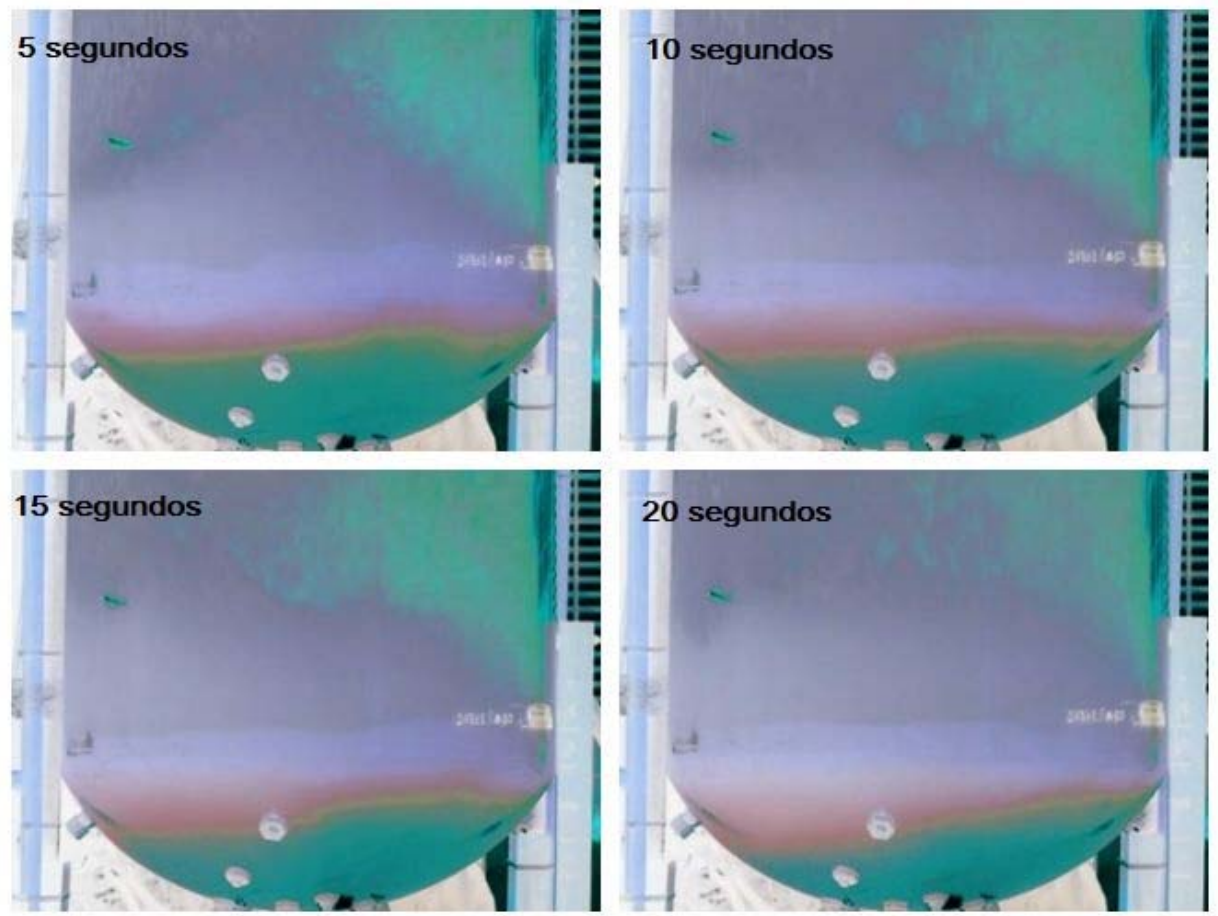

Figura 10: Primeiros 20 segundos de sopro, configuração de bico com 6 furos. 
A figura 10 ilustra o teste com bico de 6 furos, em que houve o menor valor de penetração registrado. O jato alcança um pequeno valor de penetração, se estabilizando rapidamente e gerando pouca emulsão, quando comparado aos demais testes. O sentido de rotação do banho é anti-horário.

A partir dos testes realizados foi possível notar que para maiores valores de penetração, houve uma redução na área de impacto do jato com o banho, cova ("dimple"), o que caracteriza um sopro duro, sendo este utilizado para a descarburação. Os testes com 3 e 4 furos apresentaram maior splash quando comparados aos que utilizaram bicos de 5 e 6 furos. A configuração de bico com 6 furos registrou o menor splash, caracterizando um jato com maior cova e menor geração de projeções.

Visto o grande volume ocupado por zonas estagnadas no fundo do convertedor, os testes permitem visualizar a relevância da utilização de ventaneiras submersas na pratica industrial.

A figura 11 ilustra o jato sendo despachado sobre o banho para a configuração de bico com 3 furos, onde primeiramente o jato de ar entra em contato com a camada de óleo, que oferece resistência à penetração do jato, quando comparado com a água.
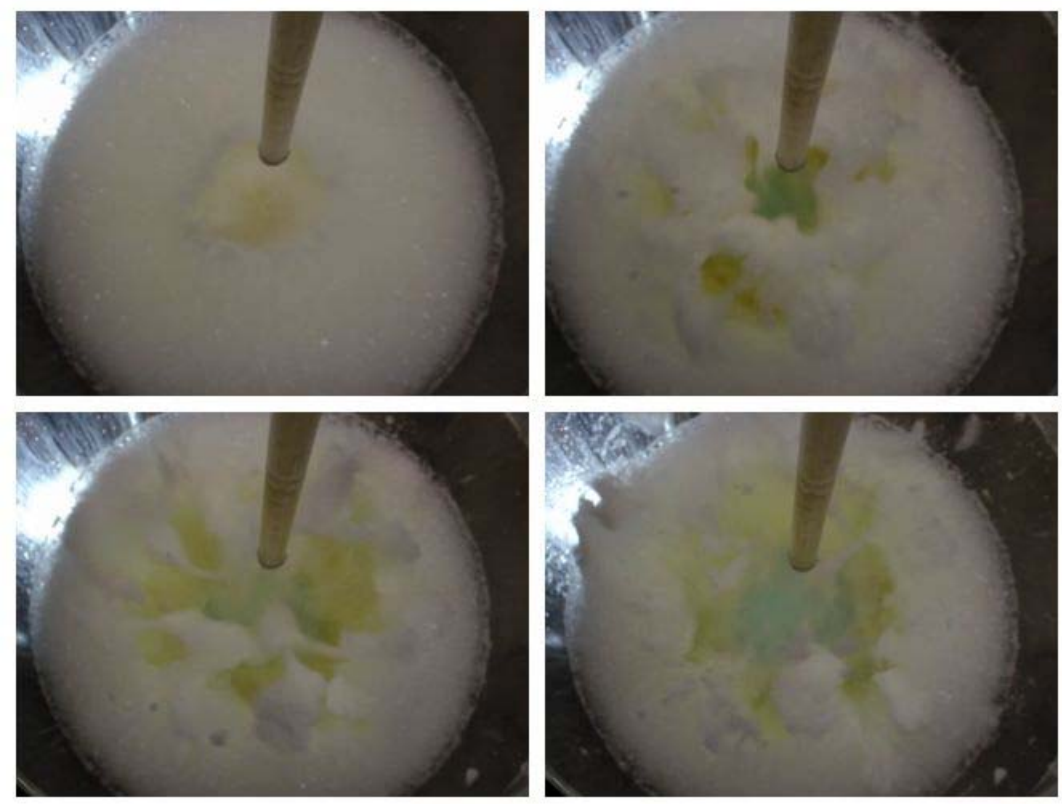

Figura 11: Impacto inicial do jato de ar no banho

Na figura 11, o jato interage com a camada de óleo e pequena fração de água, suficiente para gerar emulsão provocada pelo sabão em pó adicionado. Em seguida, gradativamente a camada de óleo de parafina e deslocada no sentido radial, expondo o banho. Então, finalmente o jato penetra na camada de água formando uma cova muitas vezes não perceptível na vista lateral. A emulsão é direcionada para as paredes do acrílico. Com a camada de óleo de parafina é possível notar redução considerável de respingos de água, simbolizando as projeções metálicas. Este resultado é semelhante ao apresentado por Li et al[11]. Para as configurações que apresentaram menor valor de penetração, observou-se que houve expansão da cova, caracterizando um sopro mole, sendo este usado para desfosforação no refino primário e potencialmente poder representar um ataque à linha dos munhões. Esse comportamento foi geral para todas as configurações, variando apenas a intensidade dos fenômenos. 
Para as quatro configurações de testes realizadas (bicos com 3, 4, 5 e 6 furos), foram encontrados diferentes valores de penetração, como representado pela figura 12.

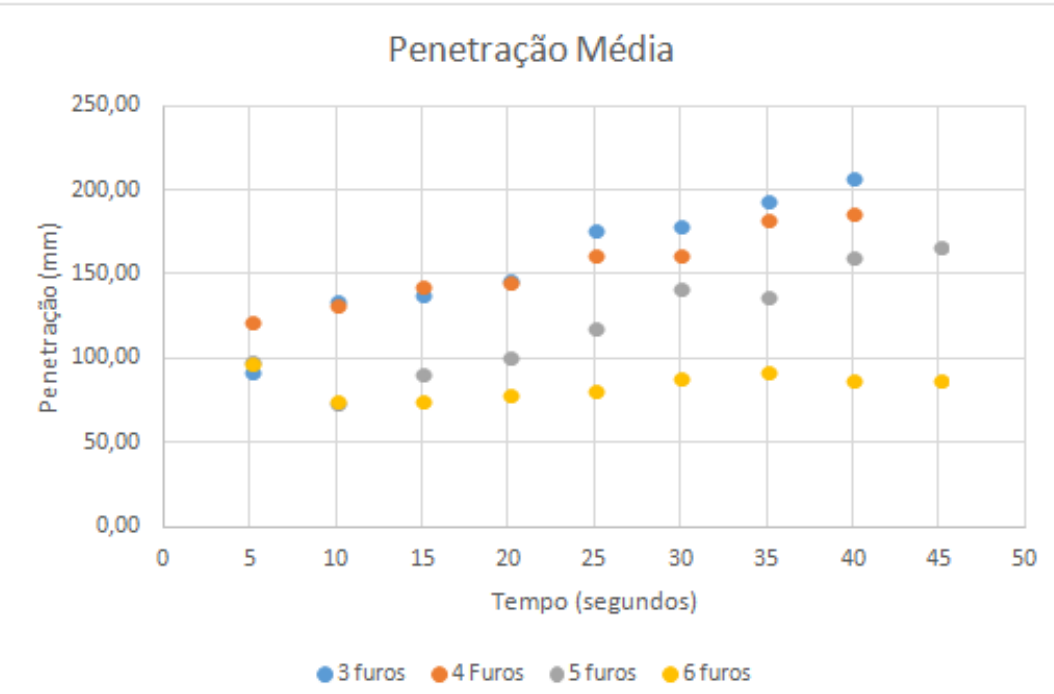

Figura 12: Penetração Media x Tempo, para as configurações de bico com 3, 4, 5 e 6 furos.

A partir do gráfico ilustrado pela figura 12, é possível verificar o comportamento semelhante da progressão de penetração do jato no banho para as diferentes configurações de bico, de forma que para bicos com 3 e 4 furos há maior penetração quando comparados com bicos de 5 e 6 furos. A configuração de bico com 6 furos, apresenta os menores valores de penetração, o que indica uma rápida estabilização do jato no banho.

A análise a seguir foi feita para cada configuração, com base nas filmagens realizadas e no gráfico apresentado na figura 12, objetivando descrever 0 comportamento da penetração do jato de ar no banho para as configurações de bicos utilizados nos testes.

\section{i. 3 furos}

Há claramente um crescimento do valor de penetração do jato de ar no banho com o decorrer do tempo, onde se registrou os maiores valores de penetração. Tal comportamento pode ser explicado pela maior viscosidade dinâmica apresentada pelo óleo de parafina (0,055 Pa.s) quando comparado com a água (0,001 Pa.s). Após vencer a barreira criada pela camada de óleo e emulsão, o jato consegue penetrar com mais facilidade na água, gerando maiores valores de penetração.

\section{ii. 4 furos}

Observou-se para a configuração de 4 furos valores elevados de penetração porem, em maior parte do tempo, menores que os apresentados pela configuração de 3 furos. Com o decorrer do tempo, os valores de penetração tendem aos máximos alcançados pelo teste com 3 furos, mas levando um intervalo de tempo maior.

\section{iii. 5 furos}

Há um comportamento progressivo da penetração semelhante à configuração de 3 furos, porém com valores inferiores. $O$ jato de ar primeiramente vence a barreira de óleo de parafina contribuindo para a formação da emulsão, penetrando na água e estabilizando o comportamento do banho. 


\section{iv. 6 furos}

Para a configuração de bico com 6 furos, há um comportamento regular, onde não há um grande valor de penetração no banho quando comparado com outras configurações. O sopro de ar apresentado pelo bico de 6 furos apresenta uma maior área de impacto sobre o banho, "dimple" e, consequentemente, uma menor energia para a penetração, fazendo com que ele se estabilize rapidamente, sem grandes variações.

\subsection{Volume Deslocado}

Como ilustrado pelas figuras $7,8,9$ e 10, há um volume no banho que permanece estagnado, sem se misturar com a emulsão gerada pela água, óleo e sabão em pó. Tal volume diminui progressivamente à medida que o jato penetra no banho, até o momento que o jato se torna estável.

A figura 13 apresenta um gráfico com o comportamento do volume misturado (volume total - volume de zonas estagnadas) versus tempo, para cada configuração de bico.

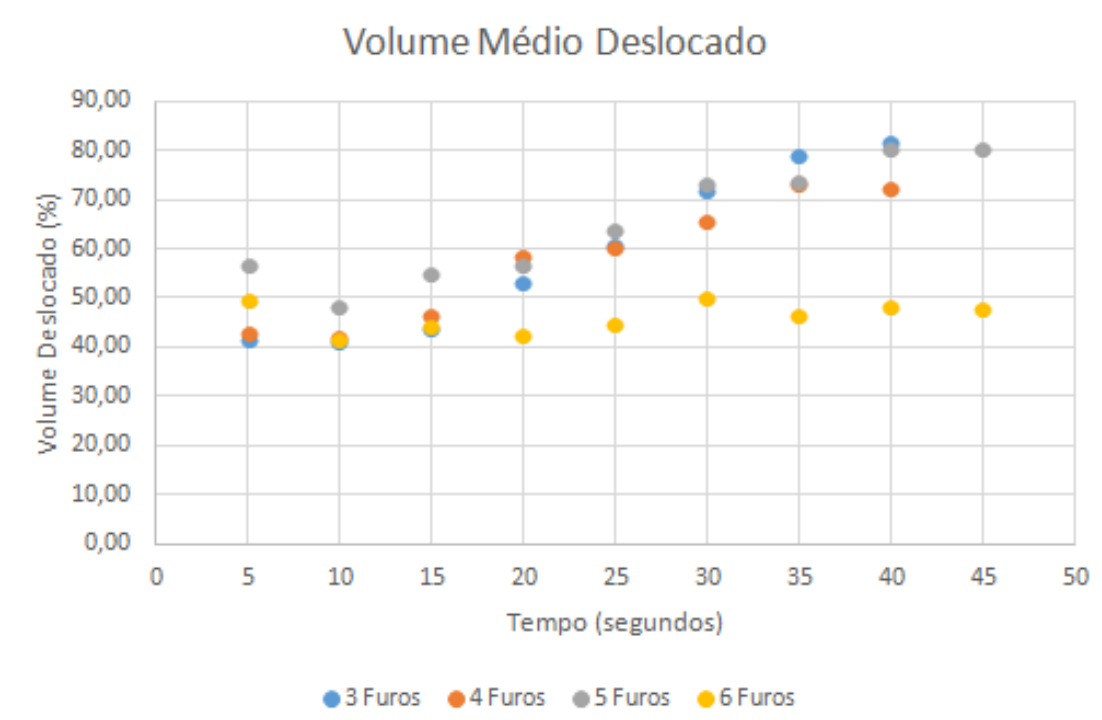

Figura 13: \% Misturada x Tempo para as configurações de bicos com 3, 4, 5 e 6 furos

Tendo como base o gráfico apresentado na figura 13, pode-se observar um comportamento de aumento progressivo do volume misturado com o tempo, semelhante ao que acontece com a penetração do jato de ar no banho.

O gráfico ilustrado na figura 13 demonstra um comportamento inicial semelhante para as configurações de 3, 4, 5 e 6 furos, onde apenas a configuração 5 apresenta maior distinção.

O comportamento estável do bico de 6 furos pode ser explicado pelo pequeno valor de penetração, o que gera menor agitação no banho quando comparado com outras configurações e consequentemente um alto volume de zonas estagnadas.

Já as configurações de 3,4 e 5 furos, demonstram uma progressão do volume misturado, de modo que com o passar do tempo, as zonas estagnadas diminuem até um valor em que se tornam constantes. 


\subsection{Constante K}

Para cada valor de penetração obtido, foi possível encontrar uma constante "K", de acordo com a equação 1. Observou-se, então, que em função do resultado da penetração, o valor de "K" variou com o tempo para todas as configurações nos tempos de testes realizados tendendo a uma estabilidade ao final dos ensaios. $O$ gráfico ilustrado pela figura 14 apresenta o valor de "K" médio para os bicos com 3 , 4,5 e 6 furos.

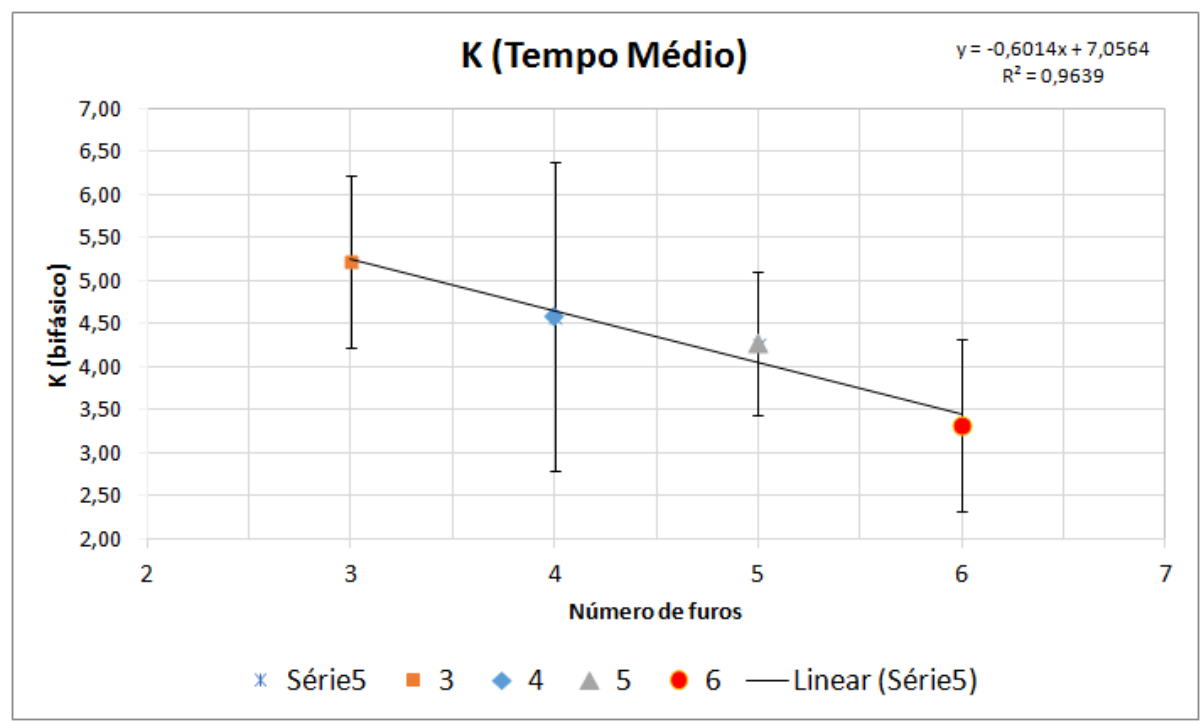

Figura 14: K médio x Número de furos

Foram consideradas nos cálculos do fator $\mathrm{K}$ as leituras de todos os intervalos de tempo, pois não ficou clara a definição de estabilidade de jato, mesmo tendo como resposta imediata o aumento do desvio padrão para cada tipo de bico. Tendo como base os resultados gerados pelo gráfico da figura 14, é possível observar que o valor do fator "K" tende a diminuir com o aumento do número de furos.

Os valores encontrados são menores, quando comparados com os resultados obtidos por Breno et $\mathrm{al}^{[10]}$, onde utilizou-se apenas água nos testes, ignorando o efeito da camada de escória e da emulsão gerada no processo. A tabela II apresenta os valores de "K" para os testes com óleo de parafina, água e sabão em pó em comparação aos realizados apenas com água (K').

Tabela II - Tabela comparativa entre testes com e sem óleo.

\begin{tabular}{|c|c|c|}
\hline Número de furos & $\begin{array}{c}\mathbf{K} \\
\text { (com camada óleo) }\end{array}$ & $\begin{array}{c}\mathbf{K}^{\prime} \\
\text { (sem camada de óleo) }\end{array}$ \\
\hline 3 & 5,225 & 5,769 \\
\hline 4 & 4,583 & 5,042 \\
\hline 5 & 4,267 & 4,663 \\
\hline 6 & 3,325 & 4,418 \\
\hline
\end{tabular}

A diferença entre os valores de K e K', sendo K o novo valor da constante empírica para testes com óleo de parafina e agua e K' para as condições de testes realizados apenas com água, podem ser explicados devido à adição da camada de óleo ao banho. Quando o jato de ar toca a camada de óleo, ele é amortecido, fazendo com 
que o jato perca energia e penetre menos no banho, representando com maior precisão os fenômenos que ocorrem na prática industrial.

\section{CONCLUSÕES}

Analisando os resultados gerados nesse trabalho, foi possível estabelecer as seguintes conclusões:

1. A camada de óleo adicionada ao banho, representando a escória, gera diminuição no valor de penetração quando comparado a testes realizados apenas com água;

2. Para bicos com menor número de furos, há um maior valor de penetração do jato no banho;

3. Jatos com menor valor de penetração geram menor agitação no banho, o que levou a um maior volume de zonas estagnadas;

4. Os valores de $\mathrm{K}$ tendem a ser menores para bicos com maior número de furos;

5. Os valores de $\mathrm{K}$ diminuem significativamente para testes realizados considerando a camada de escória e a emulsão gerada.

\section{Agradecimentos}

Os autores agradecem a Universidade Federal de Minas Gerais pelas as dependências do Laboratório de Simulação de Processos (LaSIP) e insumos para a realização dos ensaios, a Lumar Metals pelo incentivo a pesquisa continuada.

\section{REFERÊNCIAS}

1 SESHADRI, V., TAVARES, R. P., SILVA, C. A., SILVA, I. A., Fenômenos de transporte: Fundamentos e aplicações nas Engenharias Metalúrgica e de Materiais; São Paulo; Associação Brasileira de Metalurgia, Materiais e Mineração, 2010; 812 p.

2 ALMEIDA, L. P. et al. Effects of some operational parameters upon degaseification rate, mixing time, splashing and skull development in a combined-blow converter during steelmaking refining: a physical model approach. In: AISTEch $2010-$ THE IRON \& STEEL TECHNOLOGY CONFERENCE AND EXPOSITION, 2010, Pittsburgh.

Proceedings... Warrendale, PA: AIST, 2010. p. 274-85.

3 MAIA, B. T., Modelamento Físico e Matemático do Escoamento de Fluidos nos Processos BOF e EOF: Escola de Engenharia da UFMG, 2013. (Dissertação, Doutorado em Engenharia Metalúrgica e de Minas).

4 BARBOSA, F. A., Modelamento Matemático e Físico do Escoamento do Aço Líquido em Diferentes Projetos de Distribuidor do Lingotamento Contínuo da USIMINAS. Belo Horizonte: Escola de Engenharia da UFMG, 2002. 188p. (Dissertação, Mestrado em Engenharia Metalúrgica e de Minas).

5 SZEKELY, J. THEMELIS, N. J., Rate Phenomena in Process Metallurgy. 1 ed. Montreal: John Wiley \& Sons, 1971. 784p.

6 MEIDANI, A. R. N., ISAC, M., RICHARDSON, A., CAMERON, A., GUTHRIE, R. I. L. Modeling Shrouded Supersonic Jets in Metallurgical Reactor Vessels. ISIJ International, 2004, v.44, n.10, p. 1639-1645.

7 ALAM, M., IRONS, G., BROOKS, G., FONTANA, A., NASER, J., Inclined Jetting and Splashing in Electric Arc Furnace Steelmaking. ISIJ International, 2011, v.51, n.9, p. 1439-1447. 
8 MAIA, B. T., IMAGAWA, R. K., BATISTA, C. J., PETRUCELLI, A. C., TAVARES, R. P. Effects of Blow Parameters in the Jet Penetration by Physical Model of BOF Converter. AISTech 2013 Procedings. Stoughton, 2013. p.2059-2073.

9 MAIA, B. T. FAUSTINO, R. A., ABREU, G., COSTA, B., TAVARES, R. P., Efeitos dos Parâmetros de Sopro no Tempo de Mistura Utilizando Modelo Físico de Convertedor. Anais do $44^{\circ}$ Seminário de Aciaria Internacional, Araxá, Minas Gerais, Maio, 2013.

10 MAIA, B. T., PETRUCELLI, A. C., DINIZ, C. N. A., SILVEIRA, D., ANDRADE, P. H. M. S., IMAGAWA, R. K., TAVARES, R. P., Comparação da Penetração do sopro de Oxigênio em Convertedores BOF com Bicos Multifuros utilizando Modelagem Física. Seminário de Aciaria Internacional. Porto Alegre, Maio 2014.

11 LI, Q., LI, M., KUANG, S., ZOU, Z., Numerical Simulation of the Interaction Between Supersonic Oxygen Jets and Molten Slag-Metal Bath in Steelmaking BOF Process, Metallurgical and Materials Transactions B, v46B, p1494-1509, jun, 2015. 